\title{
(Sobre) vivências, saúde mental e enfrentamento à pandemia de universitários em
} vulnerabilidade socioeconômica

\author{
(About) experiences, mental health and coping the pandemic of university students in socio- \\ economic vulnerability
}

(Sobre) experiencias, salud mental y afrontamiento contra la pandemia de estudiantes universitarios en vulnerabilidad socioeconómica

Recebido: 18/10/2021 | Revisado: 25/10/2021 | Aceito: 31/10/2021 | Publicado: 01/11/2021

\author{
Carla Jesus de Carvalho \\ ORCID: https://orcid.org/0000-0002-1297-3999 \\ Universidade Estadual da Paraíba, Brasil \\ E-mail: carlapsi_@hotmail.com \\ Maria de Fátima de Araújo Silveira \\ ORCID: https://orcid.org/0000-0003-4760-201X \\ Universidade Estadual da Paraíba, Brasil \\ E-mail: fatimaasilveiraa@gmail.com
}

\begin{abstract}
Resumo
O presente estudo tem por objetivo caracterizar as repercussões psicoemocionais, os principais estressores e as estratégias de enfrentamento utilizadas por universitários acompanhados pela assistência estudantil de uma universidade pública durante a pandemia de Covid-19. Além disso, buscou-se investigar quais as dificuldades preponderantes frente às mudanças advindas com o estabelecimento do ensino remoto. A amostra foi constituída por 15 discentes. Utilizou-se a entrevista semiestruturada e a análise temática de conteúdo, proposta por Bardin. A partir das entrevistas, configurou-se 3 categorias e 6 subcategorias. A totalidade dos universitários apresentou, em diferentes intensidades, repercussões psicoemocionais após a adoção do ensino remoto e das medidas restritivas decorrentes da pandemia. Medo e ansiedade despontaram como emoções prevalentes. Verificou-se agravamento significativo do adoecimento psíquico de discentes que já apresentavam diagnóstico psiquiátrico anterior. Dentre os principais índices estressores, destacaram-se a mudança na rotina e o afastamento da rede socioafetiva. Questões de ordem econômica envolvendo, inclusive, situações de insegurança alimentar também foram mencionadas. A maioria dos estudantes avaliou negativamente o ensino remoto e apontou diversos empecilhos à adaptação deste novo sistema. Eles afirmaram que receber auxílio estudantil, durante a pandemia, influiu positivamente na permanência na universidade. Quanto às estratégias de enfrentamento adotadas para responder aos desafios desencadeados pela pandemia, fizeram parte tanto as focadas no problema quanto as com foco na emoção. Com base nos resultados obtidos, é possível concluir que o contexto da pandemia e do ensino remoto repercutiram negativamente nas vivências e na saúde mental dos estudantes em vulnerabilidade socioeconômica acompanhados pelo PNAES.
\end{abstract}

Palavras-chave: Saúde mental; Covid-19; Estudantes universitários; Ensino remoto.

\begin{abstract}
The present study aims to characterize the psycho-emotional repercussions, the main stressors and the coping strategies used by university students accompanied by student assistance at a public university during the Covid-19 pandemic. In addition, we investigated the preponderant difficulties facing the changes arising from the establishment of remote education. The sample consisted of 15 students. Semi-structured interviews and thematic content analysis proposed by Bardin were used. From the interviews, 3 categories and 6 subcategories were configured. All university students presented, in different intensities, psycho-emotional repercussions after the adoption of remote education and the restrictive measures resulting from the pandemic. Fear and anxiety emerged as prevalent emotions. There was a significant worsening of the mental illness of students who already had a previous psychiatric diagnosis. Among the main stressing indices, the change in routine and withdrawal from the socio-affective network stood out. Economic issues involving even food insecurity situations were also mentioned. Most students negatively evaluated remote learning and pointed out several obstacles to the adaptation of this new system. They stated that receiving student aid during the pandemic positively influenced their permanence at university. As for the coping strategies adopted to respond to the challenges triggered by the pandemic, both the ones focused on the problem and the ones focused on emotion were included. Based on the results obtained, it is possible to conclude that the context of the pandemic and remote education had a negative impact on the experiences and mental health of students in socioeconomic vulnerability followed by the PNAES.
\end{abstract}

Keywords: Mental health; Covid-19; University students; Remote learning. 


\begin{abstract}
Resumen
El presente estudio tiene como objetivo caracterizar las repercusiones psicoemocionales, los principales estresores y las estrategias de afrontamiento utilizadas por los estudiantes universitarios acompañados de la asistencia estudiantil en una universidad pública durante la pandemia de Covid-19. Además, se buscó investigar las dificultades preponderantes que enfrentan los cambios derivados de la implantación de la educación a distancia. La muestra estuvo formada por 15 estudiantes. Se utilizaron entrevistas semiestructuradas y análisis de contenido temático propuesto por Bardin. A partir de las entrevistas se configuraron 3 categorías y 6 subcategorías. Todos los universitarios presentaron, en diferentes intensidades, repercusiones psicoemocionales tras la adopción de la educación a distancia y las medidas restrictivas derivadas de la pandemia. El miedo y la ansiedad surgieron como emociones predominantes. Hubo un empeoramiento significativo de la enfermedad mental de los estudiantes que ya tenían un diagnóstico psiquiátrico previo. Entre los principales índices estresantes se destacó el cambio de rutina y el alejamiento de la red socioafectiva. También se mencionaron cuestiones económicas que implican incluso situaciones de inseguridad alimentaria. La mayoría de los estudiantes evaluó negativamente el aprendizaje a distancia y señalaron varios obstáculos para la adaptación de este nuevo sistema. Afirmaron que recibir ayuda estudiantil durante la pandemia influyó positivamente en su permanencia en la universidad. En cuanto a las estrategias de afrontamiento adoptadas para responder a los desafíos desencadenados por la pandemia, se incluyeron tanto las centradas en el problema como las centradas en la emoción. Con base en los resultados obtenidos, es posible concluir que el contexto de la pandemia y la educación remota tuvo un impacto negativo en las experiencias y salud mental de los estudiantes en vulnerabilidad socioeconómica seguidos por el PNAES.
\end{abstract}

Palabras clave: Salud mental; Covid-19; Estudiantes universitários; Enseñanza remota.

\title{
1. Introdução
}

A pandemia de Covid-19 representa a emergência sanitária mais significativa da história contemporânea. Ainda em curso, ela acarretou expressivas mudanças nas vivências e cotidianos das pessoas em todo o mundo, sobretudo por conta da adoção de medidas restritivas necessárias para a redução da transmissibilidade do vírus (Pereira, Selvati, Ramos, Texeira, \& Conceição, 2020).

Após um ano da notificação dos primeiros casos e mortes, ainda é difícil precisar e avaliar os impactos econômicos, sociais, políticos e humanos decorrentes deste evento. Contudo, no tocante às repercussões relativas à saúde mental, já existe uma consistente literatura (Duarte, Santo, Lima, Giordani, \& Trentini, 2020; Filgueiras \& Stults-Kolehmainen, 2020) que aponta um agravamento considerável na sintomatologia indicativa de sofrimentos psíquicos em uma parte considerável da população. No caso dos estudantes do ensino superior, grupo que já apresentava vulnerabilidades psicossociais antes mesmo da pandemia, essas repercussões incidiram de maneira mais significativa (Rodrigues, Cardoso, Peresl, \& Marques, 2020; Wang et al., 2020).

Com a suspensão de aulas presenciais e a implementação do ensino remoto, os universitários, abruptamente, tiveram que reinventar uma maneira de viver o cotidiano acadêmico. Diante de tais circunstâncias, e tendo em vista principalmente os estudantes cujas iniquidades sociais são mais marcantes, dificuldades diversas foram identificadas, a exemplo da falta de ferramentas tecnológicas e de acesso à internet, o que prejudicou o acompanhamento das atividades acadêmicas (Pereira et al., 2020) representando um entrave na operacionalização dos direitos constitucionais relativos à educação (Cipriano \& Almeida, 2020).

Neste contexto, o presente artigo tem como objetivo caracterizar as repercussões psicoemocionais, os principais estressores e as estratégias de enfrentamento utilizadas por universitários em situação de vulnerabilidade socioeconômica durante o distanciamento social decorrente da pandemia de Covid-19. Ademais, investigaram-se as dificuldades preponderantes e os fatores facilitadores frente às mudanças advindas com o estabelecimento do ensino remoto.

\section{Metodologia}

\subsection{Delineamento}

Trata-se de uma pesquisa exploratória e descritiva, com abordagem de estudo qualitativa. 


\subsection{Participantes}

O estudo foi realizado, de forma não-probabilística e por conveniência, com 15 universitários do Campus III, da Universidade Federal da Paraíba (UFPB), assumindo como critério de inclusão os alunos com matrícula ativa no período da pesquisa e contemplados com auxílios do Programa Nacional de Assistência Estudantil (PNAES). Foram excluídos aqueles discentes que não tinham acesso à internet para participar de entrevista síncrona em plataforma de vídeo-chamada.

O universo foi composto por 220 alunos que participaram do estudo I. Tal estudo, com abordagem quantitativa, intitulou-se Sofrimento psíquico e estratégias de enfrentamento de universitários acompanhados pelo Programa Nacional de Assistência Estudantil no contexto da Pandemia de Covid-19 e teve como objetivo investigar a prevalência de sintomas de ansiedade, depressão e estresse e o emprego de estratégias de enfrentamento pelos estudantes.

Os nomes dos alunos, mencionados ao longo do trabalho, foram substituídos por nomes fíctícios, com o propósito de resguardar a identidade e preservar o sigilo.

\subsection{Instrumentos}

Nesta pesquisa, utilizou-se entrevista semiestruturada, que consiste num instrumento que segue um roteiro de perguntas previamente definidas, mas que também possibilita o esclarecimento e/ou o acréscimo de questões quando o entrevistador julgar necessário (Minayo, 2010). Além disso, aplicou-se um questionário sociodemográfico, a fim de caracterizar a amostra, e um questionário com perguntas adicionais relativas à saúde mental e questões acadêmicas.

\subsection{Procedimentos e aspectos éticos}

Após a aprovação do Comitê de Ética da Universidade Estadual da Paraíba (UEPB), conforme consta no parecer $\mathrm{n}^{\circ}$ 4.268.724, da anuência dos gestores responsáveis pela instituição de ensino, obedecendo os termos das resoluções nº 466/12 e $n^{\circ}$ 510/16 do Conselho Nacional de Saúde, e concordância em participar da pesquisa por meio do Termo de Consentimento Livre e Esclarecido (TCLE) e do Termo de Autorização para Gravação de Voz (TAGV), a coleta de dados ocorreu individualmente por vídeo-chamada na plataforma online Google Meet nas duas primeiras semanas de novembro de 2020. A média de tempo para cada entrevista ficou em 45 minutos.

No final do formulário online do estudo I constava a seguinte indagação: "Você gostaria de participar de uma entrevista online (para algumas perguntas adicionais sobre o tema de pesquisa)?". Ao todo, 75 estudantes demonstraram interesse e disponibilizaram número telefônico para contato posterior. Atribuíram-se números (de 1 a 75) para cada aluno e foi realizada escolha aleatória para os que iriam participar das entrevistas, as quais foram previamente agendadas mediante disponibilidade dos participantes. Para a definição do quantitativo de quinze entrevistas, adotou-se como critério o ponto de saturação, que conclui o trabalho de campo quando se considera que as informações coletadas foram suficientes para elucidar e/ou responder a determinado objeto de indagação.

\subsection{Análise dos dados}

Para analisar os dados dos questionários foram produzidas análises descritivas. O material coletado com as entrevistas tomou como parâmetro o método proposto por Bardin (2016) de análise temática de conteúdo, o qual é composto por três fases: pré-análise, exploração do material e tratamento dos resultados obtidos e interpretação.

Inicialmente, as entrevistas foram gravadas e os áudios transcritos, o que constituiu o corpus da pesquisa. Na préanálise, empreendeu-se uma leitura "flutuante" de todo o material a fim de uma sistematização das ideias, formulação de hipóteses e objetivos, além da elaboração de indicadores que embasassem as interpretações do que foi colhido. Em seguida, na etapa da exploração, definiram-se quais seriam as unidades de codificação que, por sua vez, foram organizadas em categorias 
temáticas e em subcategorias. Por último, no tratamento dos resultados, foram realizadas as interpretações dos dados obtidos, tomando como base as referências teóricas que nortearam a pesquisa (Bardin, 2016).

\section{Resultados e Discussão}

As entrevistas abarcaram 10 estudantes mulheres e 5 homens. A média das idades foi de 23,07; com variação entre 20 e 28 anos. Apenas uma das participantes era casada; e nenhum tinha filhos. A maioria se autodeclarou parda; heterossexual; desempregada; católica; recebe auxílio moradia; e teve acesso ao auxílio emergencial no período em que a pesquisa ocorreu.

Após a análise das entrevistas, configuraram-se 03 categorias e 6 subcategorias que foram constituídas por 630 recortes de falas dos universitários participantes, conforme expostas na tabela abaixo.

Tabela 1: Categorias, subcategorias e unidades de conteúdo.

\begin{tabular}{cccc}
\hline Categorias & Subcategorias & $\begin{array}{c}\text { Unidades de } \\
\text { Conteúdo } \\
(\mathbf{f})\end{array}$ & $\begin{array}{c}\text { Unidades de } \\
\text { Conteúdo } \\
(\%)\end{array}$ \\
\hline $\begin{array}{c}\text { Repercussões da } \\
\text { pandemia }\end{array}$ & $\begin{array}{c}\text { Reações físicas e } \\
\text { psicoemocionais }\end{array}$ & 178 & 28,25 \\
\hline $\begin{array}{c}\text { Principais estressores } \\
\text { Vida acadêmica } \\
\text { durante a pandemia }\end{array}$ & $\begin{array}{c}\text { Avaliação sobre o } \\
\text { ensino remoto } \\
\text { Importância da } \\
\text { Assistência estudantil }\end{array}$ & 158 & 25 \\
\hline $\begin{array}{c}\text { Estratégias de } \\
\text { enfrentamento }\end{array}$ & $\begin{array}{c}\text { Com foco no problema } \\
\text { Com foco na emoção }\end{array}$ & 66 & 15,23 \\
\hline TOTAL & 630 & 4,6 \\
\hline
\end{tabular}

Fonte: Autores.

Ao se analisar a Tabela 1 é possível observar que Repercussões da pandemia e Estratégias de enfrentamento representaram as categorias com maiores porcentagens de falas. Já no tocante às subcategorias, Reações físicas $e$ psicoemocionais e Principais estressores foram as que apresentaram maiores quantidades de unidades de conteúdo.

\subsection{Repercussões da pandemia}

$\mathrm{Na}$ categoria Repercussões da pandemia, que é composta por 02 subcategorias e representa 53,25\% das unidades de conteúdo, enfatiza-se as principais reações psicoemocionais e estressores mencionados pelos estudantes universitários, no contexto de distanciamento social associado à pandemia de Covid-19.

\subsubsection{Reações físicas e psicoemocionais}

As manifestações físicas e psicoemocionais reportadas pelos entrevistados foram as mais diversas, incluindo desde reações e dificuldades previstas para o contexto até sintomatologia indicativa de estresse agudo e de sofrimento psíquico clinicamente significativo. Os 15 entrevistados, em graus variados, mencionaram repercussões psicológicas após a adoção das medidas de restrição de circulação.

Medo e ansiedade representaram as emoções mais referidas pelos entrevistados. Considerando especificamente o medo, os principais motivos atrelados a essa emoção foram similares aos identificados em pesquisa aplicada a universitários 
dos EUA (Son, Hegde, Smith, Wang, \& Sasangohar, 2020), quais sejam: o risco de ser infectado e o medo de infecção e de morte de familiares cujos perfis se enquadram na classificação de "grupo de risco".

“(...) a principal dificuldade só foi o medo de sair de casa no momento que precisa pra fazer uma compra, comprar alimentos principalmente, ir ao banco, pagar as contas e sair e voltar contaminado". (Pedro, 21 anos)

"O sentimento mais presente foi o medo (...) porque a minha família, o meu pai, por exemplo, tem pressão alta, aí eu tenho avós que já estão com a idade avançada, tem diabetes, essas doenças que o vírus poderia atacar mais, então o medo é justamente isso, de perder um ente querido como aconteceu com muitas famílias". (Júlia, 20 anos)

O medo é um mecanismo de proteção fundamental para a sobrevivência dos humanos, haja vista a preparação biológica diante de situações potencialmente ameaçadoras (Leahy, Tirch, \& Napolitano, 2013). Mesmo em um contexto de pandemia, essa emoção pode favorecer à adesão de medidas não-farmacológicas indicadas para a redução da suscetibilidade ao vírus, tais como o uso de máscara e o respeito às medidas de distanciamento (Duarte et al., 2020). Desta forma, reações de medo, assim como de estresse e ansiedade, são consideradas normais e esperadas diante de um contexto atípico como o do Covid-19 e tendem a diminuir a médio prazo, o que está de acordo com o relatado por alguns dos entrevistados.

Entretanto, quando exacerbadas, essas emoções podem propiciar o aumento da incidência de sofrimentos psíquicos crônicos, além de os seus impactos permanecerem por um período de tempo mais longo (Husky, Kovess-Masfety, \& Swendsen, 2020), fato que já foi constatado em epidemias anteriores (Gurvich et al., 2021). Alguns universitários afirmaram que, mesmo depois de meses de iniciada a pandemia, ainda estavam presentes dificuldades das mais diversas. Além disso, a literatura (Duarte et al., 2020; Rodrigues et al., 2020; Rogowska, Kusnierz, \& Boksczanin, 2020) indica que a pandemia pode agravar o quadro de pessoas que já possuíam antecedentes psiquiátricos. Duas entrevistadas revelaram que, antes da crise sanitária, já tinham diagnóstico psiquiátrico, sendo que ambas apresentaram um agravamento significativo, conforme transcrito no relato abaixo.

"Eu já usava medicamento e com a pandemia aumentei a dosagem e mudei de medicamento (...) eu tava sendo tratada por ansiedade e por depressão, aí nessa pandemia, com o medo em si do vírus, eu adquiri síndrome do pânico, então assim, quando eu tô com muita crise de ansiedade, muito medo de alguma coisa, aí vem aquele medo e é uma sensação horrível (...). Essa semana mesmo tive uma crise que eu só consegui levantar para ir tomar café e depois eu não consegui mais, eu não consegui mais fazer nada, nem comer, nem estudar, eu não fui produtiva em nenhum momento, só à noite que eu consegui ir tomar um banho e voltei e apaguei, e só acordei no outro dia”. (Lúcia, 27 anos)

Portanto, torna-se de extrema importância um esforço intersetorial, por parte das instituições de saúde e de educação, para a identificação de estudantes com diagnósticos psiquiátricos prévios a fim de ofertar intervenções em saúde mental alinhadas com as necessidades deles (Gundim et al., 2021). Uma medida eficaz é a disponibilização de escutas psicológicas e atendimentos psiquiátricos no formato online, sobretudo porque estudos apontam que pessoas com transtornos mentais podem ter assistência e acessos aos serviços de saúde mental restringidos durante a pandemia (Venkatesh \& Edirappuli, 2020).

Segundo Fonseca (2020), a pandemia exigiu dos sujeitos uma revisão abrupta dos modos de ser e estar no mundo, o que contribuiu para desencadear angústias, cansaço e o aumento de sintomas depressivos. A mudança de planos e a necessidade de delinear novas rotas diante das incertezas (Santos-Vitti, Bahiano, Nakano, \& Faro, 2021), além da evidente 
realidade de sofrimentos, mortes e lutos, potencializaram os sentimentos de tristeza, desânimo, desesperança e frustração dos alunos entrevistados.

\section{"Eu fiquei triste sem perceber direito, ai do nada eu ficava triste”. (Amanda, 22 anos) \\ “(...) porque eu tava muito desanimada, muito desanimada mesmo e era trancada no quarto 24 horas”. (Helena, 20 anos)}

“(...) tudo mudou, as aulas mudaram, a rotina mudou, isso mexeu muito com a minha cabeça, como se fosse destruir os planos que tinha no futuro (...) não tenho pensamento futuro não (...) o tempo vai passando, aí fico pensando: 'Meu Deus, eu tô tão atrasada, essa pandemia atrasou tudo, acabou com a minha vida'”. (Thamires, 24 anos)

Neste contexto de emergência sanitária, uma estratégia que pode auxiliar na elaboração e regulação das emoções é a disponibilização de espaços, individuais e coletivos, de acolhimento e de suporte com o objetivo de mobilizar recursos anteriores para lidar com situações adversas, facilitar o compartilhamento das vivências, validar e reconhecer o sofrimento e ampliar a resiliência. Gurvich e colaboradores (2021) sugerem que estratégias formais, tais como intervenções da terapia cognitivo-comportamental e da terapia de aceitação e compromisso, apresentam potencial dentro do contexto da pandemia de Covid-19.

Importante mencionar que, de acordo com publicação de Zhou e colaboradores (2020), o uso de plataformas online, mídias sociais e aplicativos de telessaúde se tornaram métodos úteis para a promoção da saúde mental e acolhimento das demandas de sofrimento durante esse período. No Brasil, já há publicações de experiências envolvendo projetos online vinculados a universidades, a exemplo de diferentes ações organizadas por psicólogos da Universidade Federal do Ceará (Silva, Júnior, \& Araújo, 2021) e das rodas de Terapia Comunitária Integrativa organizadas por terapeutas comunitários da Universidade Federal da Paraíba (Carneiro et al., 2020),

As principais reações cognitivas referidas pelos entrevistados foram preocupaçães, dificuldade de concentração e desorientação temporal, as quais também foram reportadas em outras publicações sobre saúde mental de universitários no contexto pandêmico (Rogowska et al., 2020; Son et al., 2020).

"É horrivel, você não tem concentração". (Isabel, 23 anos)

"Tinha dia que eu não sabia nem que dia era, qual dia da semana a gente tava, e isso influenciou bastante no meu psicológico". (Helena, 20 anos)

Problemáticas relacionadas ao sono foram registradas em quase a totalidade dos participantes (5 homens e 8 mulheres), o que está em congruência com os resultados de um recente estudo realizado com 45.161 brasileiros, o qual apontou que os participantes mais jovens foram aqueles que apresentaram maiores índices de dificuldades associadas ao sono durante a pandemia (Barros et al., 2020). No nosso trabalho, os participantes citaram sintomas como insônia, a qual foi associada, principalmente, à ansiedade e preocupações, desregulação no horário do sono e hipersonia. O estudante João (23 anos), por exemplo, mencionou que, nos primeiros meses de distanciamento social, passou a dormir de nove da manhã até as nove da noite, mantendo-se acordado durante toda a madrugada.

A relação entre qualidade de sono e saúde mental de estudantes vem sendo reportada pela literatura (Monteiro, Neto, \& Souza, 2020). Em estudo com universitários brasileiros (Coelho et al., 2020), a inexistência de uma rotina, o longo tempo 
investido em mídias digitais e as diferentes dificuldades emocionais foram os principais fatores atribuídos às irregularidades do sono, os quais coincidem com os referidos pelos entrevistados do nosso estudo. Ressalte-se que há evidências que apontam a insônia como fator de risco para transtornos mentais comuns, depressão (Baglioni et al., 2011) e ideação suicida (Botega, 2015). Além disso, uma má qualidade de sono reduz o funcionamento do sistema imunológico e a capacidade de combate a doenças infecciosas, bem como prejudica as funções cognitivas e o bem-estar geral, o que pode afetar significativamente o desempenho acadêmico (Monteiro et al., 2020).

A pandemia de Covid-19 também repercutiu nos hábitos alimentares da maioria dos estudantes desta pesquisa, com predominância no aumento do consumo de alimentos considerados por eles como "não saudáveis", a exemplo de doces, frituras e industrializados, conforme demonstrado nas falas abaixo.

"Foram mais coisas assim: massas, essas coisas, por tá na frente da TV, assistindo alguma série, então dava vontade de comer". (Matheus, 21 anos)

“(...) não sentia vontade de comer, digamos, o tradicional, eu queria tá comendo frituras, coisas que não era do meu cotidiano, as coisas industrializadas". (Valéria, 24 anos)

Corroborando resultados de pesquisa realizada com brasileiros (Werneck et al., 2021), os entrevistados reconheceram uma associação entre comportamentos sedentários, a exemplo do uso excessivo de eletrônicos e TV, e o aumento no consumo de alimentos ultraprocessados, o que se configura como fator de risco para o desenvolvimento de doenças crônicas não transmissíveis (Lima, Silva, Vilela, Rodrigues, \& Boery, 2021). A deterioração dos hábitos alimentares, durante a pandemia, está vinculada ao aumento dos níveis de ansiedade, depressão e estresse, dado também consignado por outra amostra de adultos residentes no Brasil (Filgueiras \& Stults-Kolehmainen, 2020). Além disso, como demonstra a fala a seguir, alguns alunos mencionaram o uso de alimentos com o intuito de regular emoções de ansiedade, tédio e tristeza, o que é definido na literatura como comer emocional. Tal comportamento constitui fator de risco para o desenvolvimento de episódios de compulsão e transtornos alimentares (Finger \& Oliveira, 2016).

"Mudei muito tanto a quantidade e a qualidade, eu disse a você que tava ansiosa, e querendo ou não, a gente desconta também na comida. Eu não tenho o que fazer, não sentia fome, mas sentia vontade de comer, aí o que eu fazia? Eu ia pra cozinha e fazia besteira, fazia brigadeiro, comia muito pão, pedia lanche”. (Helena, 20 anos)

Esta mudança dos hábitos alimentares aliada ao sedentarismo resultou em alteração do peso da maioria dos entrevistados, sendo que dentre aqueles que aumentaram de peso, a média foi de 5 quilos a mais e variação máxima de 10 quilos; e dentre os que perderam peso, a média foi de 5 quilos a menos. Uma das entrevistadas, com diagnóstico psiquiátrico prévio, teve redução de 12 quilos durante o período de distanciamento social.

Portanto, é de suma importância que a equipe de assistência estudantil das universidades conte com profissionais de diferentes formações, como enfermeiros, nutricionistas, psicólogos e educadores físicos a fim de que, juntos com as equipes de saúde da atenção primária dos territórios, possam planejar políticas de enfrentamento e promoção da qualidade de vida em contextos como esse.

Outros sintomas físicos também foram mencionados pelos participantes. Apenas três estudantes apresentaram sintomatologia indicativa de Covid-19, mas somente um deles realizou o teste, o qual não comprovou a doença. Dor de cabeça, sensação de falta de ar, palpitações, tremores, alergia e manchas corporais foram as reações citadas. Somatizações, 
que abarcam sintomas não explicados pela ciência médica e que são comumente associadas à dificuldade emocional, também estiveram presentes em algumas falas, o que sinaliza a necessidade de abordagens que considerem os fatores biopsicossociais no cuidado às queixas de usuários de serviços de saúde (Gracino, Louveira, Gaudioso, \& Souza, 2020).

"Quando eu me estresso muito ou tenho raiva ou fico nervosa, meio que meu corpo externaliza e enche de mancha, inclusive eu tô cheia de mancha agora, mancha roxa, e sim, eu tive muita mancha roxa, justamente porque eu não tinha como externalizar e meu corpo externalizava". (Helena, 20 anos)

"Eu tive uma alergia que até hoje eu não sei o porquê foi e fui no médico (...) não tive comprovação, mas existiu essa possibilidade dessa alergia ter sido algo relacionado ao meu emocional”. (Valéria, 24 anos)

\subsubsection{Principais estressores}

A presente subcategoria representa $25 \%$ das unidades de conteúdo, sendo que os principais estressores citados pelos entrevistados, em ordem de incidência, foram: mudanças na rotina e afastamento da rede socioafetiva; uso prolongado de telas; mídia e informações contrárias à ciência; e questões econômicas. Tais achados corroboram as descobertas de estudos anteriores com o público universitário (Rodrigues et al., 2020; Son et al., 2020). Ressalte-se que foram excluídos deste tópico aqueles estressores relativos ao ensino remoto, os quais serão apresentados posteriormente.

Por ocasião das medidas restritivas recomendadas por organizações de saúde e da suspensão das aulas online a partir do dia 17 de março (Portaria n ${ }^{\circ}$ 090, UFPB, 2020), a maior parte dos entrevistados voltou para as suas cidades, cumprindo o período de distanciamento social ao lado de seus familiares, com exceção de dois que permaneceram e vivenciaram esse contexto sozinhos. O único que não aderiu ao isolamento foi aquele que possui vínculo empregatício. Todos os demais praticaram o distanciamento prolongado e a maioria deles por dois meses ou mais.

De acordo com as falas dos universitários, a mudança brusca e significativa da rotina esteve associada a diferentes estressores. Uma das principais dificuldades foi a própria restrição de circulação e a orientação de confinamento domiciliar. Deixar de ir à universidade e a outros locais habituais, como igrejas, academias e espaços de lazer, exigiu deles a construção de novos modos de viver o cotidiano. Além disso, o afastamento da rede socioafetiva de amizade configurou-se como relevante fator estressor.

"Isso mexe muito com o psicológico porque você praticamente parou a vida pra viver em casa isolada". (Camila, 22 anos)

"A maior dificuldade talvez tenha sido essa rotina, sempre tá em quarentena, em isolamento social". (Rafael, 26 anos)

“(...) porque tipo eu moro sozinho entendeste, e eu fiquei por aqui também, era todo mundo aqui dentro desse ambiente da universidade, aí como aconteceu essa dispersão do pessoal de ter que voltar pra casa, a pessoa acaba ficando sozinho, ai isso foi o que mais senti". (Danilo, 24 anos)

Segundo Rogowska et al. (2020), embora necessárias em um contexto de pandemia, as medidas de isolamento podem acarretar sofrimento psíquico em parcela significativa da população. Considerando especificamente o público universitário, o distanciamento físico de amigos apresentou correlação com repercussões negativas na saúde mental durante a pandemia (Gundim et al., 2021). Neste sentido, torna-se de fundamental importância a adoção de estratégias, a cargo das instituições de 
ensino, a fim de amenizar essas consequências, a exemplo da utilização de tecnologias virtuais para manutenção de redes sociais de apoio.

A rotina durante a pandemia foi descrita como monótona e repetitiva pelos estudantes, uma vez que a mesma se limitou, basicamente, a dormir e acordar tarde, realizar tarefas domésticas e participar das aulas online. Apenas dois alunos praticaram atividade física regularmente durante os meses de distanciamento, e a maioria mencionou um estilo de vida menos ativo quando comparado a antes da pandemia. Destaca-se ainda a utilização de telas em grande parte do dia, especialmente de smartfones. Em média, excluindo o tempo de aulas online, os participantes ficaram seis horas e treze minutos em redes sociais, sobretudo no Instagram, quantitativo significativamente maior do que antes deste contexto pandêmico. Valéria (24 anos), por exemplo, utilizou os termos "vício", "exagero" e "dependência" para caracterizar esse uso recorrente. Sabe-se que a utilização inadequada de recursos tecnológicos pode reverberar em adoecimento psíquico com graves prejuízos para o humor, sono e vivências acadêmicas (Abreu \& Góes, 2011).

A maioria dos alunos entrevistados afirmou que só retornava às suas cidades nos finais de semana e/ou no período de férias e, devido à pandemia, eles tiveram que voltar mais cedo e conviver por longo período com os familiares. Mais da metade dos discentes relatou elevada incidência de conflitos familiares por diferentes motivos, a exemplo de desrespeito aos protocolos sanitários, cometidos principalmente pelos pais e irmãos, e interferências constantes que afetavam a concentração e realização de tarefas. Ocorrências semelhantes foram verificadas em pesquisa realizada com universitários franceses, a qual indicou que conflitos com os ocupantes da casa contribuíram significativamente para o aumento dos sintomas de estresse durante o isolamento social (Bourion-Bédès et al., 2021).

Diante de um cenário de crise sanitária, a mídia pode desempenhar relevante papel no tocante à divulgação de medidas e comportamentos amparados na ciência e que auxiliam na mitigação de consequências negativas à saúde. Contudo, há evidências consistentes de que a exposição excessiva a noticiários sobre a atual pandemia está associada a uma maior recorrência de transtornos mentais comuns e de sintomas de depressão, ansiedade e estresse (Gundim et al., 2021; Rodrigues et al., 2020), o que se coaduna com os relatos abaixo.

"Assistia bastante jornais. Até um certo momento dava pra ver a noção do que tava acontecendo, mas chegou um momento na pandemia que não dava mais pra assistir porque eu não tava aguentando mais vê aquilo lá”. (Matheus, 21 anos)

"Menina, comecei com uma crise de ansiedade quando eu escutava qualquer notícia desse Covid". (Elisa, 21 anos)

As informações inadequadas e posturas contrárias à ciência também foram mencionadas pelos estudantes como fatores estressores, ainda mais considerando o comportamento e discurso de uma parcela da população e as manifestações de grupos governistas e do próprio Presidente da República.

“(...) no nivel nacional deixou a desejar (...) foi uma postura contrária à ciência, o que diz as autoridades diante disso, eu acho que foi péssimo e agravou a nossa situação”. (Rafael, 26 anos)

“(...) a questão do Presidente, eu acho que ele foi um dos pontos que mais deixou a desejar porque era a saúde querendo fazer uma coisa e ele sendo contra, querendo fazer outra”. (Isabel, 23 anos)

Wang e colaboradores (2020) advertem que as informações sobre saúde repassadas pelo governo, durante uma crise pandêmica, devem ser coerentes, precisas e baseadas nas melhores evidências a fim de evitar reações psicológicas prejudiciais 
bem como comportamentos inadequados e contraproducentes. Ao contrário de tal recomendação e corroborando as falas reproduzidas acima, o Presidente do Brasil adotou, expressamente, postura negacionista, além de ter defendido tratamento ineficaz como principal resposta à crise (Castro et al., 2021), o que agravou a situação sanitária, econômica e social e, por conseguinte, a saúde mental da população (Gundim et al., 2021; Wang et al, 2020).

No que tange às questões econômicas, vários estudantes mencionaram diferentes dificuldades, inclusive que a renda familiar foi insuficiente para garantir a qualidade de vida durante a pandemia. Apesar de alguns terem reportado ausência de renda fixa e perda de emprego de membros da família, a principal dificuldade apontada foi a alta constante do preço dos alimentos e, em vista disso, a redução do poder de compra, o que ocasionou impacto direto nos hábitos alimentares familiares, a exemplo da diminuição do consumo de carne e frutas. Esta repercussão encontra-se em conformidade com levantamento anterior que registrou decréscimo no consumo de carne e de frutas da ordem de $44 \%$ e $41 \%$, respectivamente, por adultos, no país, durante a pandemia (Galindo et al., 2021).

“(...) a questão econômica porque a maioria dos preços aumentaram, a alimentação eu tive que mudar (...) porque eu gostava muito de ir na feira, aí a feira eu cortei, não ia mais (...) não era mais, vamos dizer assim, economicamente acessível pra mim porque ou eu comprava uma coisa que eu já comprava ou eu deixava de comprar um feijão que de 5 aumentou pra 8 reais". (João, 23 anos)

“(...) tinha tempo que a gente tava comendo tipo ovo, não tinha carne pela questão financeira”. (Helena, 20 anos)

De acordo com o Inquérito realizado pela Rede Penssan (2021), durante a crise sanitária de Covid-19, houve um recrudescimento da insegurança alimentar entre os brasileiros, atingindo 55\% do total da população do país em dezembro de 2020. Paula e Zimmermann (2021) argumentam que tal situação não é resultado único da pandemia, mas desdobramento da progressiva contenção de investimentos em políticas públicas de proteção social em uma conjuntura de grave crise sanitária, social e econômica. Este quadro impactou sobremaneira os segmentos sociais mais vulneráveis, a exemplo dos universitários atendidos por programas de assistência estudantil (Araújo, Medeiros, Vasconcelos, \& Dutra 2021). Desta forma, de acordo com Paula e Zimmermann (2021), torna-se imperativo o resgate do protagonismo do Estado e da priorização de políticas públicas de educação, de proteção social e de mecanismos de distribuição de renda.

\subsection{Vida acadêmica durante a pandemia}

Esta categoria expõe as unidades de conteúdo (19,83\% do total) relativas à avaliação do ensino remoto e à importância da política de assistência estudantil. O objetivo é indicar, com base nas falas dos entrevistados, quais foram as maiores dificuldades e fatores facilitadores ante as modificações ocorridas no modelo de ensino por conta da pandemia de Covid-19.

\subsubsection{Avaliação sobre o ensino remoto}

Como já mencionado, a UFPB suspendeu o ensino presencial em 17 de março de 2020 e aderiu ao ensino remoto emergencial. De acordo com Paiva (2020), esta é uma nomenclatura que surgiu no contexto pandêmico para configurar a mudança temporária do modelo de ensino devido às exigências impostas pela crise sanitária. Os alunos da referida instituição, os quais estavam cursando a metade do período letivo à época, migraram para o ensino remoto dias depois da anunciada suspensão. 
A maioria dos entrevistados avaliou negativamente o ensino remoto e destacou que há diferenças relevantes de qualidade entre as aulas online e o ensino presencial, o que, segundo os mesmos, afetou o desempenho e a aprendizagem.

"O ensino remoto eu acho assim uma coisa péssima (...) porque é uma coisa muito superficial, principalmente a gente que é uma coisa prática, a gente do curso de Agroindústria, que é prático-teórica”. (João, 23 anos)

"Então eu avalio o período remoto mais negativamente, inclusive nesse último período eu só tava com três disciplinas e eu reprovei em uma delas, isso nunca tinha acontecido". (Amanda, 22 anos)

"Não me adaptei de forma alguma, achei péssimo (...) principalmente o aprendizado, não estou aprendendo de verdade nada (...) não consigo me concentrar no computador”. (Elisa, 21 anos).

A mudança abrupta e a inexistência de preparação para a utilização de ambientes e tecnologias virtuais de aprendizagem, tanto da parte dos docentes quanto dos próprios discentes, foram pontuadas como aspectos desfavoráveis à adaptação ao novo contexto. Além disso, houve alunos que reportaram a incompreensão e falta de flexibilidade de alguns professores quanto às dificuldades e limitações dos estudantes. Destacaram também o emprego de metodologias tradicionais e pouco interativas, a indisponibilidade de gravação das aulas e o precário acesso ao docente para elucidação de dúvidas, conforme exemplificam os discursos abaixo.

“(...) pra ser sincera, o fator de risco que influenciou de forma negativa a minha saúde mental foi os professores, não todos, mas já conheci muito professor durante essa pandemia que me deu muita vontade de desistir do curso, eu me sentia incapaz". (Thamires, 24 anos)

"Alguns professores, eles simplesmente colocam os slides, lá no Google Meet e fica só lendo e aquilo é muito chato, já é chato você assistir aquilo passando aula de slide em presencial, e virtual é pior ainda (...) então, para mim, a metodologia influenciou muito". (Isabel, 23 anos)

"Alguns professores não gravavam aquela aula, então se você perdesse não teria como mais ter acesso, alguns não entendiam que os alunos, se chovesse, não ia ter internet, quem morasse na zona rural geralmente não tinha acesso à internet, então eu acho que essas pequenas coisas, pequenas não, que faz totalmente a diferença, foi que contribuiu pra não ser um periodo melhor". (Lúcia, 27 anos)

Já existe literatura disponível, a exemplo da publicação de Paiva (2020), que apresenta sugestões para qualificar o ensino remoto. Algumas propostas incluem a aplicação de metodologias ativas de aprendizagem, o estabelecimento de espaço destinado a uma interação social informal e a possibilidade de os alunos participarem de proposições de tarefas e mecanismos de avaliação. Além disso, é imprescindível a construção de um ambiente educacional acolhedor, humanizado e que não negligencie nem invalide as emoções e as dificuldades do alunado, sobretudo nesta época de intensos sofrimentos.

Quase metade dos participantes não teve acesso a computadores durante este período e, apesar do acesso à internet por todos, a maioria relatou conexão de baixa qualidade, o que afetou sobremaneira a participação nas aulas síncronas bem como a realização dos trabalhos acadêmicos. Tal desigualdade virtual, que atinge especialmente os alunos em vulnerabilidade socioeconômica, está correlacionada ao aumento de estresse emocional na atual pandemia (Silva et al., 2021). Cipriano e Almeida (2020), ao considerarem que os direitos constitucionais alusivos à educação desse público estão sendo desrespeitados, 
enfatizam a urgência da implementação de políticas públicas de intervenção que possam oportunizar um acesso de qualidade ao ensino remoto.

Corroborando descobertas de estudos anteriores (Bourion-Bédès et al, 2021; Pereira et al., 2020; Silva et al., 2021), os demais pontos negativos mencionados pelos participantes foram: ambiente inadequado para os estudos, ambientes ruidosos que afetavam a concentração, excesso de atividades acadêmicas, dificuldade na gestão de tempo e na gerência entre as atividades do curso e as outras demandas da rotina e a frustração quanto ao atraso na finalização da graduação.

Acrescido a tais fatores, a continuação das atividades acadêmicas foi correlacionada, por alguns estudantes, a um comprometimento do nível de bem-estar emocional, o que se coaduna com resultados de estudo realizado com universitários brasileiros, os quais apresentaram aumento de estresse associado à manutenção dessas atividades (Patias, Hohendorff, Cozzer, Flores, \& Scorsolini-Comin, 2021).

“(...) às vezes, eu tinha até crises de ansiedade antes da aula (...) era muito sério quanto que eu só tava ali porque era obrigatório”. (Lúcia, 27 anos)

"Eu acho que eu precisava só lidar com meus sentimentos e não precisava lidar com responsabilidades ainda, ainda mais porque fiquei um tempo parada, então assistir às aulas eu acho que foi, sim, uma coisa prejudicial". (Amanda, 22 anos)

Conquanto tenham mencionado diversos fatores negativos, a grande maioria dos universitários se mostrou favorável a não interrupção das aulas durante o período de distanciamento social. Ademais, eles ressaltaram também pontos positivos no prosseguimento do período letivo, a exemplo de as aulas servirem como uma atividade que contribuiu para "ocupar" a mente e "distrair" do contexto de sofrimento pandêmico. Os horários das aulas síncronas funcionaram também como balizador da rotina, estimulando, inclusive, a prática de comportamentos saudáveis.

“Quando voltou a rotina da faculdade me obriguei a dormir mais cedo”. (Maria, 28 anos)
“(...) eu sei que não acabou a pandemia, mas eu já tô estudando, tenho com que ocupar a mente”. (Helena, 20 anos)

Dentre os motivos que favoreceram a adaptação às aulas remotas, destacam-se: gravação e posterior disponibilização das aulas síncronas, redução do quantitativo de atividades solicitadas, realização de trabalhos em duplas e, principalmente, a priorização de métodos ativos de aprendizagem. Achados similares foram registrados em estudo de Dosea, Rosário, Silva, Firmino e Oliveira (2020), no qual se verificou que 90\% dos universitários entrevistados avaliaram positivamente as experiências vivenciadas em aulas cujos professores utilizaram métodos ativos de aprendizagem na modalidade online.

\subsubsection{Importância da assistência estudantil}

Ao serem indagados se receber o auxílio pelo PNAES, durante a pandemia, fez alguma diferença para a permanência na universidade, apenas um estudante afirmou que não, tendo em vista já estar concluindo o curso de graduação. Todos os demais afirmaram que o auxílio influiu positivamente na permanência acadêmica, o que está em consonância com a finalidade do programa (Brasil, 2010).

"Se não tivesse o auxílio, com certeza, não continuaria no curso, não teria como continuar se não fosse o auxílio". (Maria, 28 anos, uma das alunas que veio do Sudeste exclusivamente para cursar graduação) 
“Acho que se não fosse o auxílio, teria desistido totalmente do curso”. (Isabel, 23 anos)

Os entrevistados destacaram que, há dois meses, a Pró-Reitoria de Assistência Estudantil da universidade publicou editais de auxílio-instrumental e auxílio-inclusão digital. Graças aos valores recebidos por meio desses editais, assim como do auxílio emergencial do governo federal, foram possíveis a aquisição de equipamentos de tecnologia de informação e a compra de dados móveis com serviços de internet, o que qualificou o acesso às aulas durante o período de ensino remoto.

"Por meio desse auxílio consegui colocar uma internet banda-larga e pagar pra assistir as aulas". (Matheus, 21 anos)

“Como eu disse, o meu marido ficou um mês sem trabalhar, então ajudou muito e ajudou muito no total. Inclusive ajudou a consertar o meu computador com os dois auxílios [instrumental e emergencial], que tinha ficado quebrado no meio do outro período suplementar. Então se não fosse eles dois eu não conseguiria continuar com os estudos no total”. (Amanda, 22 anos)

Houve relatos de discentes afirmando que o valor do auxílio do PNAES também contribuiu sobremaneira para a compra de itens indispensáveis, tais como medicamentos e alimentos.

"Se eu estou com o medicamento [psiquiátrico] em dia e tudo organizado foi de certa forma por conta do auxílio porque eu não iria ter condições de tudo aumentar e lá em casa a gente não tem renda fixa, então foi de extrema importância porque meu tratamento hoje se eu perdesse esse auxílio hoje eu teria que parar”. (Lúcia, 27 anos)

“O auxílio fez total diferença. Por ter ali uma renda entre aspas, qualquer dificuldade que a sua família passasse, você sabia que poderia ajudar justamente nos custos, porque com a pandemia parou muita coisa, meu pai é feirante, açougueiro, então parou e tivemos dificuldades em relação a isso”. (Júlia, 20 anos)

"Eu pagava meu aluguel e ainda sobrava um pouquinho para ajudar aqui em casa porque os alimentos estão com um preço absurdo, tá tudo muito caro e eu vi as coisas apertarem. Você perguntou se afetou a renda, não é a questão de afetar a renda, é de as coisas estarem muito caras, tipo, você ir no supermercado, o que antes comprava com 50 reais, hoje em dia passa de 100, a inflação aumentou tudo, aí é como eu lhe disse, ajudou um pouco aqui a minha família, não foi muita coisa, mas ajudou”. (Helena, 20 anos)

Desta forma, a importância do programa de assistência estudantil, no contexto da crise sanitária e econômica associada à pandemia de Covid-19, não se limitou apenas à ampliação das condições de permanência dos estudantes em vulnerabilidade socioeconômica. Contribuiu também para minimizar riscos sociais e prover as necessidades básicas dos alunos e de suas famílias. De maneira similar, em estudo realizado com 84 estudantes acompanhados pela assistência estudantil e que permaneceram em residências universitárias da USP, durante a pandemia, os que receberam algum auxílio (estudantil, emergencial ou Bolsa Família) apresentaram menor frequência de insegurança alimentar (Araújo et. al., 2021), o que ratifica a relevância de ações governamentais e concessão de auxílios financeiros em contextos não-habituais. No tocante à saúde mental, existem evidências (Silva, Cardoso, Saraceno, \& Almeida, 2015) de que investimento em políticas de segurança social, durante e após períodos de crise econômica, também afeta positivamente o bem-estar psíquico da população. 
Convém salientar que o programa de assistência estudantil encontra-se ameaçado pelo atual quadro de contingenciamento de recursos das universidades públicas brasileiras, mais notadamente após a fixação de um teto de gastos orçamentários para os próximos vintes anos, conforme estabeleceu a Emenda Constitucional n ${ }^{\circ}$ 95/2016. Para 2021, por exemplo, estima-se uma redução de aproximadamente 1 bilhão de reais para essas instituições, o que poderá comprometer a ampliação do direito à assistência estudantil e, consequentemente, à permanência e conclusão do curso universitário por alunos em vulnerabilidade socioeconômica (Santos, Abrantes, \& Zonta, 2021).

\subsection{Estratégias de enfrentamento}

Com 26,82\% das unidades de conteúdo, esta categoria apresenta as estratégias que os estudantes utilizaram para se adaptar e responder aos desafios e às situações estressoras associadas à pandemia. Os recursos empregados mostraram-se alinhados ao modelo teórico de coping (Lazarus \& Folkman, 1984), o qual indica duas grandes categorias de enfrentamento: estratégias focadas no problema e aquelas com foco na emoção.

\subsubsection{Estratégias focadas no problema}

O grupo de estratégias focadas no problema refere-se à execução de uma ação a fim de administrar ou alterar a situação estressante (pandemia) ou as suas consequências. Deste modo, as principais estratégias adotadas pelos entrevistados foram: práticas de autocuidado, cumprir protocolos de biossegurança, planejar e focar em metas e buscar por suporte instrumental.

Apesar de as já citadas dificuldades e mudanças significativas da rotina, alguns entrevistados, sobretudo após os cinco primeiros meses de quarentena, empreenderam práticas de autocuidado, tais como a realização de atividade física, higiene do sono, alimentação saudável e a identificação e respeito aos próprios limites. Eles atribuíram o aumento do bem-estar físico e psicológico a essas mudanças, o que é corroborado por estudos anteriores (Bourion-Bédès et al., 2021; Rogowska et al., 2020). Alunos também mencionaram que, antes da pandemia, não dispunham de tempo para práticas de autocuidado e que um ponto positivo advindo da flexibilização dos horários com o ensino remoto foi justamente a possibilidade de cuidarem mais e melhor de si mesmos.

"Passei a cuidar mais de mim (...) do meu sono, praticar exercício fisico, acho que isso foi uma coisa que me ajudou". (Camila, 22 anos)

“(...) me dar prioridade foi um dos pontos que melhorou muito nessa pandemia, eu sempre esquecia de mim e resolvia tudo de todas as pessoas (...) então me dar prioridade foi essencial”. (Lúcia, 27 anos)

Alguns entrevistados pontuaram que focar em metas e planejar a rotina, a exemplo de anotar e gerenciar os horários das atividades, foi uma estratégia que contribuiu para minimizar o estresse. Além disso, uma outra forma de enfrentamento à pandemia que alguns adotaram foi seguir as orientações de biossegurança das autoridades sanitárias, conforme as falas abaixo.

"Assim eu buscava sempre sair de máscara, higienizar as mãos periodicamente quando tava fora de casa". (Pedro, 21 anos)

"Acredito que seguir as normas que os profissionais de saúde diziam, tomar os cuidados, tudo isso aumentava a minha proteção (...) usar máscara, álcool em gel, cumprir a quarentena”. (Rafael, 26 anos) 
Em pesquisa realizada na China (Wang et al., 2020), o uso de máscara esteve correlacionado a níveis mais baixos de ansiedade e depressão. Inferiu-se que tal uso apresentou benefícios psicológicos uma vez que proporciona uma maior sensação de segurança. Justo-Henriques (2020) assinala que intervenções da Psicologia da Saúde podem contribuir para que as pessoas assumam comportamentos saudáveis e preventivos em contextos epidêmicos e pandêmicos.

Todos os alunos que participaram da pesquisa são SUS-dependentes, sendo que dois deles, ao necessitar de algum procedimento não-urgente, preferem recorrer a serviços privados alegando que as instituições de saúde pública são deficitárias no tocante ao acesso. Especificamente durante a quarentena, a maior parte deles precisou de algum tipo de atendimento, inclusive de assistência por profissionais de saúde mental, que ocorreu sobretudo por psicólogos e psiquiatras da universidade por meio de atendimentos online, e-mail e/ou por telefone.

“O acompanhamento tanto psicológico quanto com o psiquiatra foram essenciais para mim”. (Lúcia, 27 anos)

“(...) era muito bom quando [a psicóloga] mandava e-mail perguntando como era que tava, era muito bom mesmo, parava um momento e pronto, tava assim e assado, ai eu parava e olhava 'ah, não tá tão ruim quanto eu imaginava' porque ali eu colocava e via realmente como é que tava". (João, 23 anos)

O último relato ratifica publicação de Zhou e colaboradores (2020), os quais indicam evidências positivas que embasam o uso do sistema de telessaúde, incluindo meios de comunicação simples como e-mail e mensagens de texto para disponibilizar apoio e psicoeducação em saúde mental durante a pandemia de Covid-19.

\subsubsection{Estratégias focadas na emoção}

O enfrentamento do contexto pandêmico também se observou com a aplicação de estratégias centradas na emoção, as quais objetivam regular as respostas emocionais ao problema. Neste segmento, destacaram-se a busca de suporte social por motivos emocionais, distração e busca por significado.

Apoio emocional advindo da rede socioafetiva é reportado pela literatura como uma das principais e mais eficazes estratégias de enfrentamento durante contextos atípicos (Bourion-Bédès et al., 2021; Stanislawski, 2019). Um estudo de Patias e colaboradores (2021), por exemplo, realizado com universitários brasileiros, apontou que esse tipo de auxílio esteve associado a melhores níveis de bem-estar durante a pandemia de Covid-19. No nosso estudo, o apoio emocional de familiares e amigos também se configurou como o principal recurso utilizado pelos estudantes.

“(...) muitas vezes, eu não conseguia comer e elas [amigas] me ligavam pra me distrair, me animar (...) por whatsapp, até pelo meet mesmo, às vezes, a gente conversava, abria uma reunião e era só para conversar, pra tentar animar". (Lúcia, 27 anos)

“(...) eu sou muito apegada à minha mãe e ela foi a que eu mais tive apoio emocional”. (Júlia, 20 anos)

Tal como ocorrera em descobertas anteriores (Son et al., 2020), distrair-se foi outra estratégia bastante citada pelos participantes e que contribuiu para a redução dos impactos emocionais decorrentes da pandemia. Como evidenciam as falas transcritas abaixo, as atividades foram as mais diversas, a exemplo de assistir lives, filmes e séries, escutar música, ler, apreciar a natureza, cuidar de animais e realizar trabalhos manuais e hobbies. 
"A distração também ouvindo música, assistindo série, porque dá uma outra perspectiva, a gente vê o filme que acaba bem, a gente pensa que as coisas vão ficar bem novamente”. (Amanda, 22 anos)

“(...) eu tentei criar esse hábito, é que aqui na varanda do apartamento a gente consegue ver o pôr do sol, aí quando dá umas cinco horas eu vou lá e respiro um ar, eu não sei o que tem no efeito da luz do sol que dá um up’. (Maria, 28 anos)

"Eu inventei assim, pra relaxar, fazer origami, foi uma das saidas que ajudou bastante, a gente começava a tentar fazer outra coisa de artesanato, fazia barquinho de palito de picolé que ocupava nosso tempo todinho, aí foi bem assim que deu para gente levar”. (João, 23 anos)

Segundo Lazarus e Folkman (1984), ao se deparar com um evento estressante, o significado que as pessoas atribuem à vida pode sofrer relevantes mudanças. A utilização desta estratégia influi na regulação emocional, na recuperação do senso de controle e no reajuste dos propósitos de vida de pessoas que vivenciaram contextos de desastres naturais. Alguns participantes do nosso estudo revelaram que a pandemia acarretou clarificação dos valores e mudanças no significado das vivências.

“Acredito que depois disso tudo, um vírus mundial que infelizmente levou a vida de muitas pessoas (...) a gente tem que dar uma respirada, parar para pensar no que tá fazendo da vida, não viver no automático, contemplar, aproveitar aqueles momentos, viver realmente (...) não esperar vim isso de novo pra aproveitar, pra dar valor, pra dizer que sentiu saudade ou que quer ver alguém”. (Thamires, 24 anos)

“(...) já refleti que, às vezes, a gente tem que valorizar mais as coisas, as pessoas, coisas simples e pequenas e agora nesse momento a gente sentiu falta de muita coisa, de muitos momentos que a gente achava que era insignificante $e$ viu que não era insignificante”. (Isabel, 23 anos)

Vale ressaltar ainda que, com menor incidência, os alunos referiram a utilização das seguintes estratégias: religiosidade, expressão de emoções como otimismo, gratidão e esperança, aceitação, negação, controle emocional e uso de medicamentos psiquiátricos.

Por fim, ao ser indagado sobre o que o teria auxiliado a lidar com a saúde mental e bem-estar, um dos alunos que cumpriu o distanciamento social sozinho, mencionou o uso de álcool. Segundo afirmou, sair para encontrar com amigos em bares foi a estratégia adotada para enfrentar o sentimento de solidão. Porém, tal estratégia implica fatores de risco adicionais, tanto por torná-lo mais suscetível a contrair o vírus, quanto pela possibilidade de desenvolver padrões comportamentais deletérios devido ao uso continuado de bebidas alcoólicas.

“(...) não vou mentir, a bebida me ajudou porque tipo por conta da questão dos amigos a pessoa que bebe sempre tá num barzinho, dificilmente eu tô sozinho (...) e aí essa questão de tá em barzinho, bebedeira, isso a pandemia me trouxe muito, porque tipo eu já bebia antes, mas eu hoje bebo muito, bem mais que o dobro, tipo se eu bebia duas vezes por semana, agora eu tô bebendo quatro, entendeste?”. (Danilo, 24 anos)

O aumento no consumo de álcool e outras drogas, durante a pandemia, já havia sido reportado em estudo com a população geral no Brasil (Serafim et al., 2021). Contudo, este é um enfrentamento caracterizado como evitativo e tem sido correlacionado a impactos negativos e ao aumento de estresse em estudantes universitários (Bourion-Bédès et al., 2021). 


\section{Considerações Finais}

A pandemia de Covid-19 e o ensino remoto repercutiram de maneira significativa nas vivências e na saúde mental dos estudantes que participaram do presente estudo. Os resultados aqui apresentados devem ser considerados por equipes multiprofissionais da assistência estudantil e da rede de atenção primária do SUS, no momento do planejamento de políticas de enfrentamento e atenção à saúde mental e qualidade de vida dos estudantes. Enquanto perdurarem o distanciamento social e o ensino remoto, espaços online (individuais e coletivos) de acolhimento e escuta devem ser priorizados.

No âmbito do ensino remoto emergencial, levando-se em consideração que a pandemia ainda está em curso no Brasil e que não há previsão de retorno presencial das aulas em grande parte das instituições públicas de ensino superior, torna-se necessário o investimento em estratégias para minimizar as dificuldades identificadas. Sobretudo, no tocante à educação continuada dos docentes, com priorização de metodologias ativas de aprendizagem e de formações que priorizem estratégias de acolhimento e uma educação centrada nas pessoas e nas relações. Ademais, precisam ser ampliadas as políticas públicas que visem a garantia do acesso de qualidade ao ensino remoto para todos os universitários.

O cenário atual da pandemia no Brasil (que apresenta uma das maiores médias de mortes diárias do mundo), o aumento de casos associados à nova variante Delta e um empobrecimento crescente da população tornam imprescindível a ampliação de programas de assistência estudantil para todos que deles necessitem. As restrições orçamentárias impostas à educação, em especial neste contexto atípico, podem gerar novos processos de exclusão, constituindo um obstáculo à democratização do acesso e permanência estudantil, o que fere os direitos constitucionais relativos à educação. Vale ressaltar que as áreas previstas no PNAES não se restringem somente à concessão de auxílios pecuniários, mas também abarca ações voltadas para a promoção de saúde mental de alunos em vulnerabilidade socioeconômica.

A limitação do presente estudo decorre da realização da pesquisa no formato online, o que pode ter inviabilizado a participação daqueles discentes que não conseguiram acesso à internet. Além disso, as descobertas não podem ser generalizadas tendo em vista que o período da coleta ocorreu no final da primeira onda da pandemia e existem mudanças substanciais ao longo dos diferentes momentos da crise, a exemplo das restrições impostas pelas autoridades sanitárias, do acesso e valor do auxílio emergencial bem como outros fatores econômicos e sociais.

Reiteramos que a saúde mental dos universitários não foi atravessada apenas por questões individuais, familiares e decorrentes do contexto de desastre sanitário. Os sofrimentos também estiveram correlacionados com decisões e condutas negacionistas de gestores, processos de exclusão e desigualdade virtuais, situações de insegurança alimentar e fatores de risco potencializados pela própria universidade. Portanto, ter conhecimento desses determinantes sociais, econômicos e institucionais da saúde mental dos estudantes pode contribuir para a formulação de políticas de promoção à saúde e redução de iniquidades sociais.

Ressalte-se, pois, que é indispensável, no contexto universitário, promover medidas de cuidado à saúde mental que não se limitem, como é frequente nos dias de hoje, ao ensino de habilidades socioemocionais e à disponibilização de atendimentos individuais por psicólogos e psiquiatras. É fundamental que sejam criados espaços de trocas afetivas, de fortalecimento de pautas democráticas e de práticas protetivas e propiciadoras de saúde mental, que contemplem as emoções e necessidades dos universitários, inclusive as de condições dignas de vida e de garantia de direitos sociais, como educação e assistência estudantil.

Por último, sabendo-se que a pandemia de Covid-19 ainda está em curso, recomenda-se a realização de estudos com contornos longitudinais, que abarquem indicadores de saúde mental, estratégias de enfrentamento utilizadas por universitários em diferentes momentos, fatores de risco e de proteção à saúde mental de estudantes vulneráveis socioeconomicamente, bem como avaliação de programas de saúde mental implementados no contexto da crise sanitária. 


\section{Agradecimentos}

Ao Programa de Pós-Graduação em Psicologia da Saúde (PPGPS) da Universidade Estadual da Paraíba (UEPB) e à Universidade Federal da Paraíba (UFPB), Campus III.

\section{Referências}

Abreu, C. N., \& Góes, D. S. (2011). Dependência de internet. In B. Rangé (Org.), Psicoterapias cognitivo-comportamental: um diálogo com a psiquiatria (2a. ed.). Artmed.

Araújo, T. A., Medeiros, L. A., Vasconcelos, D. B., \& Dutra, L. V. (2021). (In) segurança alimentar e nutricional de residentes em moradia estudantil durante a pandemia do covid-19. Segurança Alimentar e Nutricional, 28(00). http://doi.org/10.20396/san.v28i00.8661200

Baglioni, C., Battagliese, G., Feige, B., Spiegelhalder, K., Nissen, C., Voderholzer, U., Lombardo, C., \& Riemann, D. (2011). Insomnia as a predictor of depression: a meta-analytic evaluation of longitudinal epidemiological studies. Journal of Affective Disorders, 135(1-3), 10-19. https://doi.org/10.1016/j.jad.2011.01.011

Bardin, L. (2016). Análise de conteúdo. Edições 70.

Barros, M. B. A., Lima, M. G., Malta, D. C., Szwarcwald, C. L., Azevedo, R. C. S., Romero, D., \& Gracie, R. (2020). Relato de tristeza/depressão, nervosismo/ansiedade e problemas de sono na população adulta brasileira durante a pandemia de Covid-19. Epidemiologia e Serviços de Saúde, 29(4). https://doi.org/10.1590/S1679-49742020000400018

Botega, N. J. (2015). Crise suicida: avaliação e manejo. Artmed.

Bourion-Bédès, S., Tarquinio, C., Batt, M., Tarquinio, P., Lebreuilly, R., Sorsana, C., \& Baumann, C. (2021). Stress and associated factors among French university students under the COVID-19 lockdown: the results of the PIMS-CoV 19 study. Journal of Affective Disorders. 283 , 108-114. https://doi.org/10.1016/j.jad.2021.01.041

Brasil, C. N. S. (2012). Resolução $n^{o}$ 466/12. Diretrizes e normas regulamentadoras de pesquisas envolvendo seres humanos. https://bvsms.saude.gov.br/bvs/saudelegis/cns/2013/res0466_12_12_2012.html

Brasil. C. N. S. (2016). Resolução $n^{\circ}$ 510/16. Dispõe sobre as normas aplicáveis a pesquisas em Ciências Humanas e Sociais. https://www.in.gov.br/materia//asset_publisher/Kujrw0TZC2Mb/content/id/22917581

Brasil, M. E. (2010). Decreto $n^{o}$ 7234. Dispõe sobre o Programa Nacional de Assistência Estudantil - PNAES. Brasília: Ministério da Educação. http://www.planalto.gov.br/ccivil_03/_ato2007-2010/2010/decreto/d7234.htm

Carneiro, A. L. B., Ramos, S. C. S., Ribeiro, R. M., Melo, C. M. B., Melo, M. N. A., Aguiar, P. K. F., \& Falcão, P. B. L. (2020). Terapia comunitária integrativa em tempos de pandemia: encontros, encantos, (con) vivências e partilhas que transcendem as telas. Research, Society and Development, 9(11). http://doi.org/10.33448/rsd-v9i11.9785

Castro, M. C., Kim, S., Barberia, L., Ribeiro, A. F., Gurzenda, S., Ribeiro, K. B., \& Singer, B. H. (2021). Spatiotemporal pattern of Covid-19 spread in Brazil. Science, 372, 821-826. https://doi.org/10.1126/science.abh1558

Cipriano, J. A., \& Almeida, L. C. C. S. (2020). Educação em tempos de pandemia: análises e implicações na saúde mental do professor e aluno. In Congresso Nacional de Educação, Maceió, AL, Brasil, 8. https://editorarealize.com.br/editora/anais/conedu/2020/TRABALHO_EV14 0_MD1_SA18_ID6098_31082020204042.pdf

Coelho, A. P. S., Oliveira, D. S., Fernandes, E. T. B. S., Santos, A. L. S., Rios, M. O., Fernandes, E. S. F., \& Fernandes, T. S. S. (2020). Saúde mental e qualidade do sono entre estudantes universitários em tempos de pandemia da COVID-19: experiência de um programa de assistência estudantil. Research, Society and Development, 9(9). https://doi.org/10.33448/rsd-v9i9.8074

Dosea, G. S., Rosário, R. W. S., Silva, E. A., Firmino, L. R., \& Oliveira, A. M. S. (2020). Métodos ativos de aprendizagem no ensino online: a opinião de universitários durante a pandemia de Covid-19. Interfaces Científicas, 10(1), 137-148. https://doi.org/10.17564/2316-3828.2020v10n1p137-148

Duarte, M. Q., Santo, M. A. S., Lima, C. P., Giordani, J. P., \& Trentini, C. M. (2020). Covid-19 e os impactos na saúde mental: uma amostra do Rio Grande do Sul, Brasil. Ciência \& Saúde Coletiva, 25(9), 3401-3411. https://doi.org/10.1590/1413-81232020259.16472020

Filgueiras, A., \& Stults-Kolehmainen, M. (2020). Factors linked to changes in mental health outcomes among brazilians in quarantine due to COVID-19. MedRxiv (preprint). https://doi.org/10.1101/2020.05.12.20099374

Finger, I. R., \& Oliveira, M. S. (2016). A prática da terapia cognitivo-comportamental nos transtornos alimentares e obesidade. Novo Hamburgo: Sinopsys.

Fonseca, D. C. (2020). Ser e estar em um mundo pandêmico: marcas da Covid-19 na subjetividade. Revista Interdisciplinar de Direitos Humanos, 8(2), 111120. https://doi.org/10.5016/ridh.v8i2.17

Galindo, E., Teixeira, M. A., De Araújo, M., Motta, R., Pessoa, M., Mendes, L., \& Rennó, L. (2021). Efeitos da pandemia na alimentação e na situação da segurança alimentar no Brasil. Food for Justice Working Paper (Series, n. 4). Berlin: Food for Justice: Power, Politics, and Food Inequalities in a Bioeconomy. https://doi.org/10.17169/refubium-29554

Gracino, Y. L. L., Louveira, M. H., Gaudioso, C. E., \& Souza, J. C. (2020). Transtornos somatoformes durante a pandemia de Covid-19. Research, Society and Development, 9(9). http://doi.org/10.33448/rsd-v9i9.8019 
Gundim, V. A., Encarnação, J. P., Santos, F. C., Santos, J. E., Vasconcellos, E. A., \& Souza, R. C. (2021). Mental health of university during the COVID-19 pandemic. Revista Baiana de Enfermagem, 35. https://doi.org/10.18471/rbe.v35.37293

Gurvich, C., Thomas, N., Thomas, E., Hudaib, A., Sood, L., Fabiatos, K., \& Kulkarni, J. (2021). Coping styles and mental health in response to societal changes during the COVID-19 pandemic. International Journal of Social Psychiatry, 67(5), 540-549. https://doi.org/10.1177/0020764020961790

Husky, M. M., Kovess-Masfety, V., \& Swendsen, J. D. (2020). Stress and anxiety among university students in France during Covid-19 mandatory confinement. Comprehensive Psychiatry, 102. https://doi.org/10.1016/j.comppsych.2020.152191

Justo-Henriques, S. (2020). Contributo da Psicologia da Saúde na promoção de comportamentos salutogénicos em pandemia. Psicologia, saúde \& Doenças, 21(2), 297-310. http://doi.org/10.15309/20psd210206

Lazarus, R. S., \& Folkman, S. (1984). Stress, appraisal and coping. Springer.

Leahy, R. L., Tirch, D., \& Napolitano, L. A. (2013). Regulação emocional em psicoterapia: um guia para o terapeuta cognitivo-comportamental. Porto Alegre: Artmed.

Lima, E. R., Silva, T. S. S., Vilela, A. B. A., Rodrigues, V. P., \& Boery, R. N. S. O. (2021). Implicações da pandemia de Covid-19 nos hábitos alimentares de brasileiros: revisão integrativa. Research, Society and Development, 10(4). https://doi.org/10.33448/rsd-v10i4.14125

Minayo, M. C. S. (2010). O Desafio do conhecimento: pesquisa qualitativa em saúde. Hucitec.

Monteiro, B. M. M., Santos Neto, C. N., \& Souza, J. C. (2020). Sono e cronotipo em estudantes universitários na pandemia da Covid-19. Research, Society and Development, 9(9). http://doi.org/10.33448/rsd-v9i9.7688

Paiva, V. L. M. O. (2020). Ensino remoto ou ensino à distância: efeitos da pandemia. Estudos Universitários: revista de cultura, 37(1-2), 58-70. http://doi.org/10.51359/2675-7354.2020.249044

Patias, N. D., Hohendorff, J. V., Cozzer, A. J., Flores, P. A., \& Scorsolini-Comin, F. (2021). Mental health and coping strategies in undergraduate students during COVID-19 pandemic. Trends in Psychology, 29, 414-433. https://doi.org/10.1007/s43076-021-00069-z

Paula, N. M., \& Zimmermann, S. A. (2021). A insegurança alimentar no contexto da pandemia da Covid-19 no Brasil. Revista NECAT, 10(19), 55-66. Recuperado de https://revistanecat.ufsc.br/index.php/revistanecat/article/view/4849/3608

Pereira, R. M. S., Selvati, F. S., Ramos, K. S., Texeira, L. G. F., \& Conceição, M. V. (2020). Vivência de estudantes universitários em tempos de pandemia do Covid-19. Revista Práxis, 12(1), 47-56. https://doi.org/10.47385/praxis.v12.n1sup.3458

Rede Penssan. (2021). VIGISAN: Inquérito Nacional sobre Insegurança Alimentar no Contexto da Pandemia da Covid-19 no Brasil. Rio de Janeiro: Rede Penssan. Recuperado de http://olheparaafome.com.br/VIGISAN_Inseguranca_alimentar.pdf

Rodrigues, B. B., Cardoso, R. R. J., Peres, C. H. R., \& Marques, F. F. (2020). Aprendendo com o Imprevisível: saúde mental dos universitários e educação médica na Pandemia de Covid-19. Revista Brasileira de Educação Médica, 44. https://doi.org/10.1590/1981-5271v44.supl.1-20200404

Rogowska, A. M., Kusnierz, C., \& Bokszczanin, A. (2020). Examining anxiety, life satisfaction, general health, stress and coping styles during COVID-19 pandemic in Polish sample of university students. Psychology Research and Behavior Management, 13, 797-811. https://doi.org/10.2147/PRBM.S266511

Santos, C. C. B., Abrantes, P. P. M., \& Zonta, R. (2021). Limitações orçamentárias: desafios à assistência estudantil da UNB em tempos de pandemia. Cadernos Cajuína, 6(3), 213-227. Recuperado de https://cadernoscajuina.pro.br/revistas/index.php/cadcajuina/article/view/503/433

Santos-Vitti, L., Bahiano, M. A., Nakano, T. C., \& Faro, A. (2021). Repercussões e consequências psicológicas no contexto da Covid-19. In A. Faro, E. Cerqueira-Santos, \& J. P. Silva (Orgs.), Psicologia e Covid-19: saúde, desenvolvimento e educação. Belo Horizonte: Editora Dialética.

Serafim, A. P., Durães, R. S. S., Rocca, C. C. A., Gonçalves, P. D., Saffi, F., Cappellozza, A., ... Lotufo-Neto, F. (2021). Exploratory study on the psychological impact of COVID-19 on the general Brazilian population. PLoS ONE, 16(2). https://doi.org/10.1371/journal.pone.0245868

Silva, L. S., Júnior, P. R. M., \& Araújo, F. E. N. (2021). Ensino superior em tempos de pandemia: sofrimento, culpa e (im) produtividade. In F. Negreiros, B. O. Ferreira (Orgs.), Onde está a psicologia escolar no meio da pandemia? São Paulo: Pimenta Cultura.

Silva, M., Cardoso, G., Saraceno, B., \& Almeida, J. C. (2015). A saúde mental e a crise econômica. In P. Santana (Org.), Território e saúde mental em tempos de crise. Coimbra: Imprensa da Universidade de Coimbra.

Son, C., Hegde, S., Smith, A., Wang, X., \& Sasangohar, F. (2020). Effects of COVID-19 on college students' mental health in the United States: interview survey study. Journal of Medical Internet Research, 22(9). https://doi.org/10.2196/21279

Stanislawski, K. (2019). The Coping Circumplex Model: na integrative modelo f the structure of coping with stress. Frontiers in Psychology, 10. https://doi.org/10.3389/fpsyg.2019.00694

UFPB. (2020). Portaria $n^{\circ}$ 090, de 2020. Dispõe sobre as medidas de prevenção e adequação do funcionamento da Universidade Federal da Paraíba às determinações oficiais referentes à emergência de saúde pública decorrente do Coronavírus (COVID-19). https://www.ufpb.br/temp/copy_of_Portaria090GRReitoriaUFPB.pdf

Venkatesh, A., \& Edirappuli, S. (2020). Social distancing in covid-19: what are the mental health implications? BMJ, 369. https://doi.org/10.1136/bmj.m1379

Wang, C., Pan, R., Wan, X., Tan, Y., Xu, L., Ho, C. S., \& Ho, R. C. (2020). Immediate psychological responses and associated factors during the initial stage of the 2019 Coronavirus Disease (COVID-19) epidemic among the general population in China. International Journal of Environmental Research and Public Health, 17(5). https://doi.org/10.3390/ijerph17051729 
Research, Society and Development, v. 10, n. 14, e288101421955, 2021

(CC BY 4.0) | ISSN 2525-3409 | DOI: http://dx.doi.org/10.33448/rsd-v10i14.21955

Werneck, A. O., Silva, D. R., Malta, D. C., Gomes, C. S., Souza-Júnior, P. R. B., Azevedo, L. O., \& Szwarcwald, C. L. (2021). Associations of sedentary behaviours and incidence of unhealthy diet during the Covid-19 quarantine in Brazil. Public Health Nutrition, 24(3), 422-426. https://doi.org/10.1017/S1368980020004188

Zhou, X., Snoswell, C. L., Harding, L. E., Bambling, M., Edirippulige, S., Bai, X., \& Smith, A. (2020). The role of telehealth in reducing the mental health burden from Covid-19. Telemedicine and e-Health, 26(4), 377-379. https://doi.org/10.1089/tmj.2020.0068 